\title{
Bifurcation of the mandibular canal- Radiological appreciation of a rare anatomical variation - Report of 3 cases and review of the literature
}

\author{
Gunasena $\mathrm{C}^{1}$, Madurapperuma MASW ${ }^{1}$, Anupama $\mathrm{S}^{1}$, Hettiarachchi PVKS ${ }^{1}$, Jayasinghe $\mathrm{RD}^{1}$ \\ ${ }^{1}$ Department of Oral Medicine and Periodontology, Faculty of Dental Sciences, University of \\ Peradeniya
}

\begin{abstract}
The mandibular canal is a single canal that runs in the mandible carrying inferior alveolar neuro vascular bundle and splitting of the mandibular canal into in its course is rare occurrence. With the advent of 3-dimensional imaging modalities like computed tomography or cone-beam computed tomography better visualization becomes possible. As a result, more cases of this nature are being reported in the recent past giving rise to increased prevalence than in the past where twodimensional imaging like digital panoramic tomography were dominating. This article also appreciates the radiological anatomy of three cases with bifurcation of the mandibular canal incidentally diagnosed in the cone-beam computed tomography and also discusses the clinical significance of this rare anatomical entity.
\end{abstract}

\section{Introduction}

The mandible is a unique piece of anatomy that had amazed both the anatomists and clinicians due to its structure and multitude of functions it performs. The mandible being the second bone to begin ossification in the body ossifies approximately in the $6-7^{\text {th }}$ week of intrauterine development.[1] Cartilage formation tends to occur as clusters from the Meckel's cartilage and then unify to form a single bone. In both humans and primates, this ossification process completes in the first year after birth. [2] Mandibular canal is formed by the encapsulation of bone during embryogenesis. [2]

The mandibular canal originates from the mandibular foramen in the posterior aspect of mandible and terminates at the mental foramen in the anterior aspect of mandible and it carries the inferior dental nerve, artery, and vein. .[1] It is a single canal, running anteriorly, through the trabecular bone, to the level of the alveolus of the mandibular central incisor, near the mental foramen.[1] The canal is wide and narrows towards the medial side. [1,2] It is known that the mandibular foramen can have variations, but rare in nature.[3] It can be in the form of the bifid, trifid, double mandibular canal, and pseudo bifid/double mandibular canal. [3] The reason for these variations in the mandibular canal is related to the embryological formation of the inferior dental nerve (IDN) in the mandible.[4]

Radiologically, the mandibular canal is characterized by a radiolucent strip in between two radio-opaque lines, generally, it is a single structure observed in different positions of the mandible and around the mandibular third molar. [3]

The incidence of a bifid mandibular canal is dependent on the method of radiological investigation such as Dental panoramic 
Gunasena C, Madurapperuma MASW, Anupama S, Hettiarachchi PVKS, Jayasinghe RD - Bifurcation of the mandibular canalRadiological appreciation of a rare anatomical variation - Report of 3 cases and review of the literature

tomography (DPT) and Cone-beam Computed Tomography (CBCT). There are several classifications describing the bifurcation of mandibular canal (BMC). BMC was first described in 1973 by Pattierson [7].

The presence of BMC has many clinical implications and such as knowledge of variations in the course of the mandibular canal is important in lower impacted third molar removal surgery, implant placement in the posterior mandible, orthognathic surgery, when managing the failure of IDN block and as a differential diagnosis in pain in posteriorly resorbed alveolar ridges caused by the pressure exerted by dentures [5].[6][8].[9].
Here, we report three cases of BMC which was identified incidentally to appreciate its radiological anatomy and literature to understand this entity.

\section{Case history}

In all 3 cases, the bifurcation of the mandibular canal was diagnosed from the referrals for evaluating the risk of Inferior dental canal damage in lower mandibular third molar removal surgery by evaluating the Cone Beam Computed Tomography (CBCT) images.

Details of the 3 cases are summarized in table 1.

Table 1 - Clinical and radiological summary of the cases

\begin{tabular}{|c|c|c|l|l|}
\hline $\begin{array}{c}\text { Case } \\
\text { Number }\end{array}$ & Age & Gender & $\begin{array}{c}\text { Presenting } \\
\text { complaint }\end{array}$ & $\begin{array}{l}\text { Radiological interpretation of the mandibular } \\
\text { canal (CBCT) }\end{array}$ \\
\hline 1 & 24 & M & $\begin{array}{l}\text { Pain from a left } \\
\text { side wisdom } \\
\text { tooth. }\end{array}$ & $\begin{array}{l}\text { The left inferior alveolar canal (IAC) appears to } \\
\text { be bifid. It divides into two, posterior to the Left } \\
\text { side lower third molar and gives out a lingual } \\
\text { branch. The said lingual branch crosses the } \\
\text { mandible immediately posterior to the Left side } \\
\text { lower third molar. (figure 1 \& 2) }\end{array}$ \\
\hline 2 & 25 & F & $\begin{array}{l}\text { Impacted right } \\
\text { side wisdom } \\
\text { tooth }\end{array}$ & $\begin{array}{l}\text { The right IDN canal has a buccal path away from } \\
\text { the roots of the right-side lower third molar. An } \\
\text { accessory canal is given out apically in relation } \\
\text { to the 48 and travels lingually (figure 3 \& 4) }\end{array}$ \\
\hline 3 & 55 & M & $\begin{array}{l}\text { Pain on right } \\
\text { side lower jaw. }\end{array}$ & $\begin{array}{l}\text { The right IDN canal has a buccal path away from } \\
\text { the roots of the right-side lower third molar. An } \\
\text { accessory canal divides from the main canal } \\
\text { posterior to the 48, and travels lingually. (figure } \\
5 \text { \& 6) }\end{array}$ \\
\hline
\end{tabular}




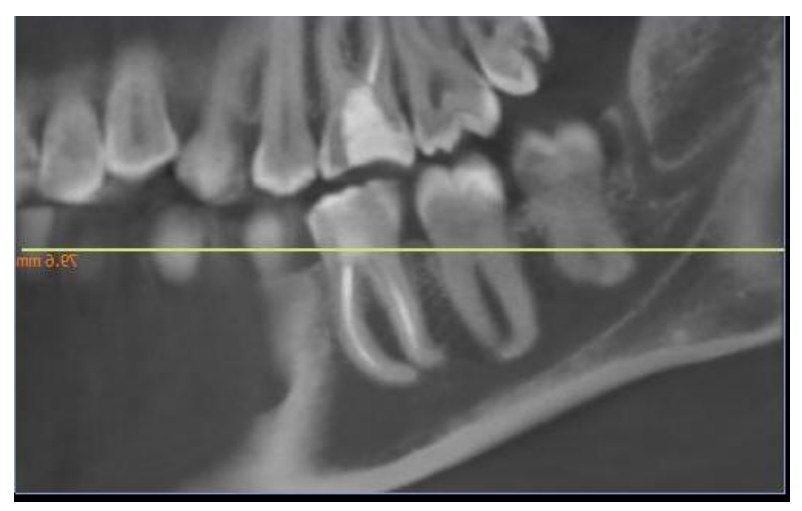

Figure 1 - Pseudo Panoramic section of CBCT showing the pathway the IDN of case number 1

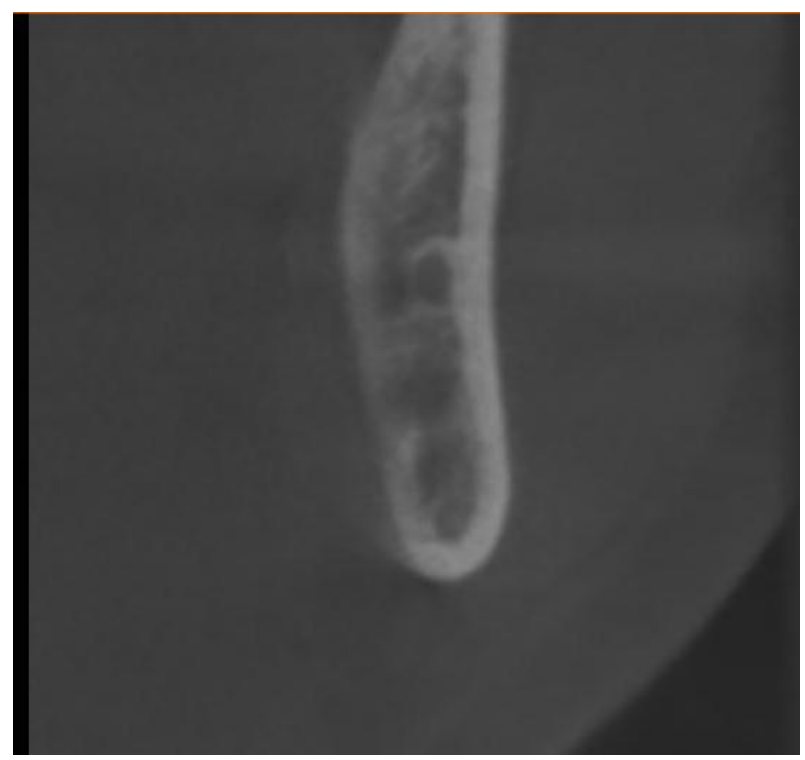

Figure 2 - Coronal view of CBCT showing the pathway the IDN of case number 1

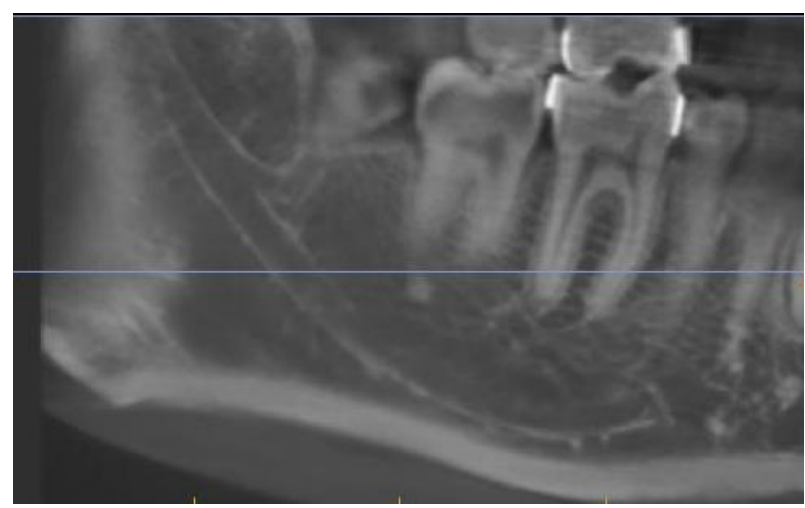

Figure 3 - Pseudo Panoramic section of CBCT showing the pathway the IDN of case number 2

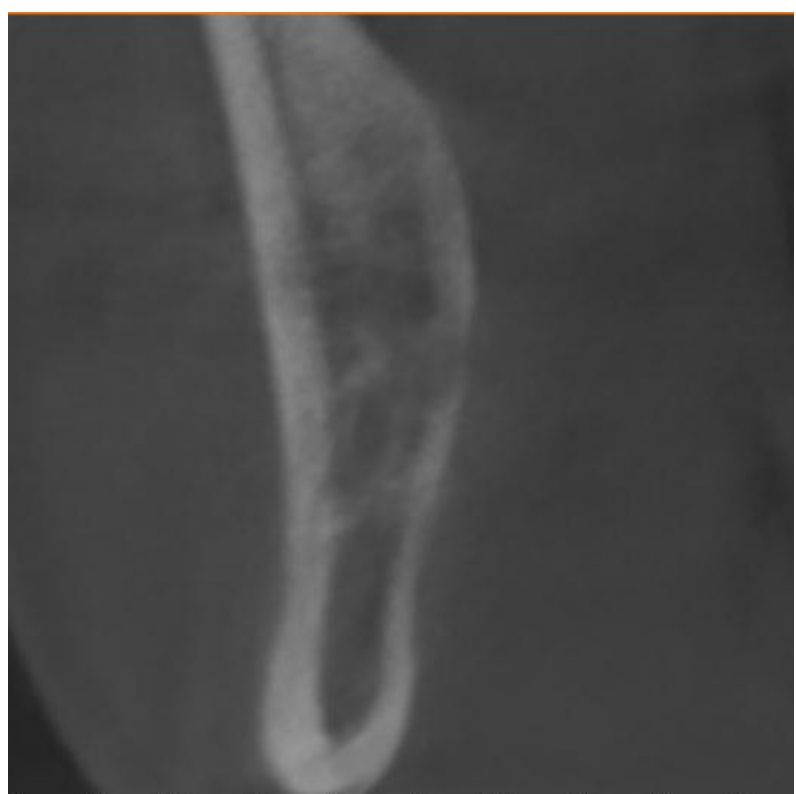

Figure 4 - Coronal view of CBCT showing the pathway the IDN of case number 2

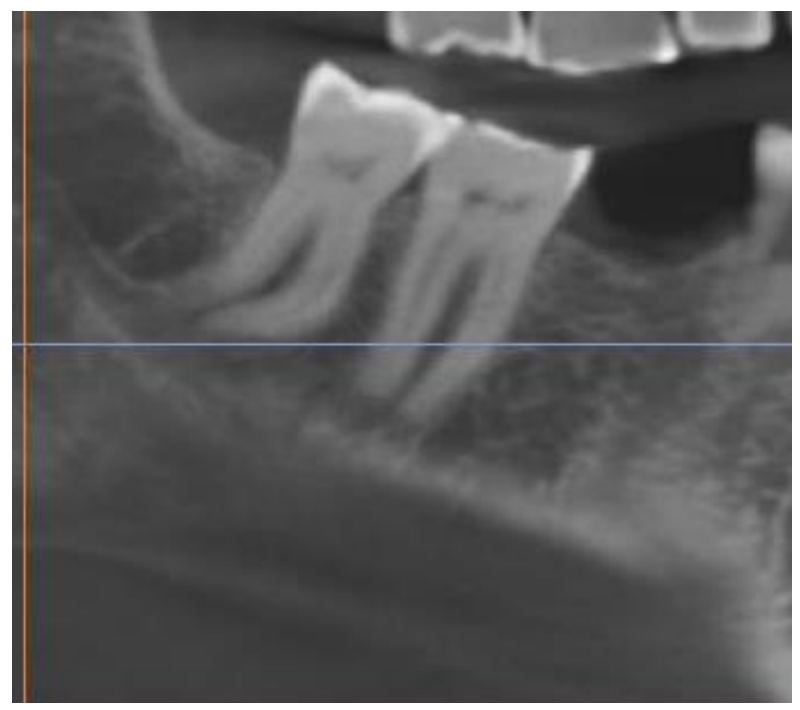

Figure 5 - Pseudo Panoramic section of CBCT showing the pathway the of case number 3 


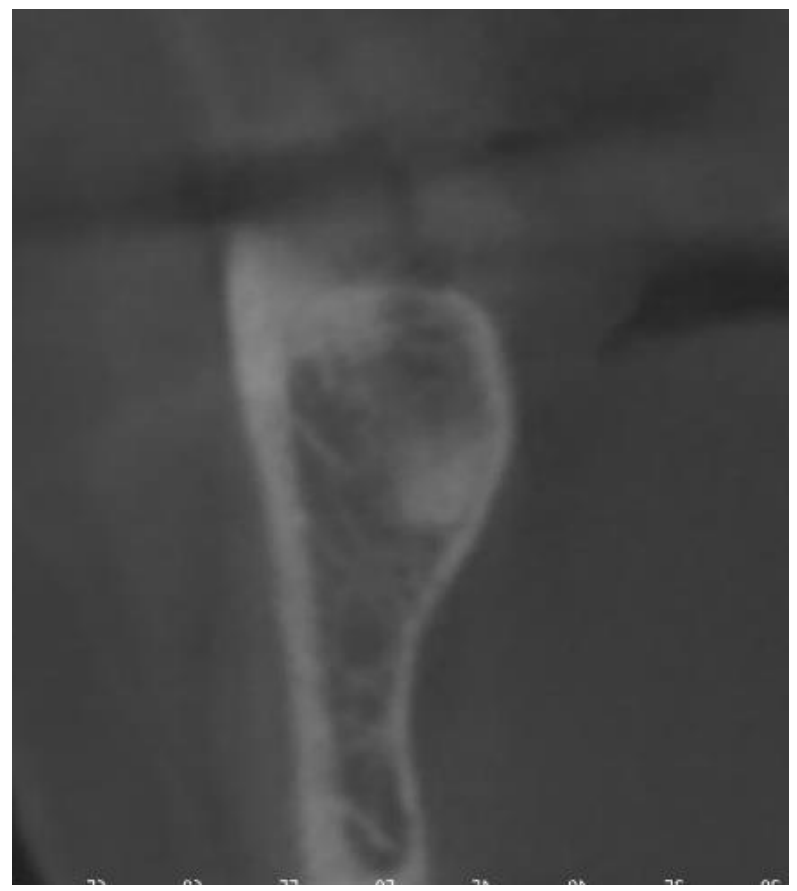

Figure 6 - Coronal view of CBCT showing the pathway the IDN of case number 3

\section{Discussion}

The origins of the bifid mandibular canal can be comprehended by understanding its embryology. There are 3 IDN canals that form in the course of embryonic development to innervate each of the groups of teeth in one half of the mandible. This development is followed in time by the fusion of the nerves. This theory would explain the as existence of double mandibular canals in some patients, secondary to incomplete fusion of these 3 nerves. This was discussed by Chavez et al. [4]

CBCTs provide 3-dimensional images where multiple cut sections could be analyzed, further details can be obtained and superimposition can be avoided.[8] Many authors say that CBCT is a better imaging modality than DPT for spotting BMC in the mandible. Normal anatomical structures have been reported to be superimposed, under or falsely reported, or not clearly seen in panoramic radiographs.[8] Kuribayashi et al. show that due to the narrow nature of the accessory canal of the BMC could be missed in OPG but not in CBCT so the prevalence could be more which was 15.6\%.[10] Bogdán et al and Klinge et al provide more information on this through a cadaveric study. [11] Freitas et al had found a $30 \%$ prevalence of bifid mandibular canals in a sample of 300 in a CBCT study.[8] This raises a concern about its rare nature of the bifid mandibular canal. This sheds light on a gap of knowledge that is worth exploring.

Carter and Keen, Nortje and Langlais et al are the classification methods used in the classification of BMC.[12] Langlais et al classification is most commonly used as it was based on large sample numbers. [3] (table 2) According to this classification, our 3 cases belong to type 1 , which is the more prevalent type as the division occurs before the root of the impacted mandibular third molar.

Table 2 - Describes Langlais et al bifurcation of the mandibular canal.[3]

\begin{tabular}{|l|l|}
\hline Type & Description \\
\hline Type I & $\begin{array}{l}\text { Single foramen Duplicated canal } \\
\text { to third molar region }\end{array}$ \\
\hline Type II & To the ramus of the mandible \\
\hline Type III & Combination of I and II \\
\hline Type IV & $\begin{array}{l}\text { Separate foramina Duplicated } \\
\text { canal }\end{array}$ \\
\hline
\end{tabular}

Understanding the anatomical variations of the mandibular canal is important for a dental surgeon. A possible cause for local anesthesia 
failure during inferior dental nerve block is the existence of accessory nerve supply due to bifid or trifid mandibular canal.[5] If this occurs, it should be radiologically investigated and confirmed. The same can be said during the exodontia of the impacted mandibular third molar, the relationship of the impacted tooth and IDN canal should be evaluated and the presence of bifid canal should be looked upon and also its relationship with the root of the impacted tooth. [5] With this understanding, the surgical technique for the removal of the impacted mandibular third molar should be planned, so that IDN canal damage may be avoided. Also, the same can be stated in the placements of dental implants in the posterior mandible. A gradual alveolar ridge resorption in the posterior aspect of the of the mandible by denture wearing caused compression of an accessory branch of the mandibular canal can cause pain. [13]

The identification and understanding of this variation of the mandibular canal is important for a maxillofacial surgeon or plastic surgeon as well, especially when performing bilateral sagittal split osteotomy in the orthognathic surgical correction of the defects of the mandible.[14]

Complications such as traumatic neuroma, paresthesia, and bleeding can occur due to the ignorance of this variation. [15]

The prevalence of bifid mandibular canal is rare but with the advent of better threedimensional modalities, this premise may be questionable. Further investigations are warranted. The appreciation of the anatomy of this entity is important for the management of the IDN block failures. Also, for performing extraction of impacted lower third molars, placement of posterior implants, and performing bilateral sagittal split osteotomy in orthognathic surgery to prevent IDN canal damage.

\section{Funding}

None

\section{Conflicts of interest}

None

\section{Acknowledgments}

None

\author{
Corresponding Author \\ C. Gunasena, \\ Department of Oral Medicine and \\ Periodontology, \\ Faculty of Dental Sciences, \\ University of Peradeniya. \\ Peradeniya, Sri Lanka.
}

Tel: 0776120616

E-mail: cgunasena039@gmail.com.

\section{BY 4.0}

This is an Open Access article distributed under the terms of the Creative Commons Attribution 4.0 license (unless stated 
Gunasena C, Madurapperuma MASW, Anupama S, Hettiarachchi PVKS, Jayasinghe RD - Bifurcation of the mandibular canalRadiological appreciation of a rare anatomical variation - Report of 3 cases and review of the literature

otherwise) which permits unrestricted use, distribution and reproduction in any medium, provided the original work is properly cited. Copyright is retained by the author(s).

\section{References}

1. sinnatamby, C. S., \& last, r. J. (1999). Last's anatomy: regional and applied. Edinburgh, Churchill Livingstone.

2. Sadler, T. W., and Jan Langman. 2004. Langman's medical embryology. Philadelphia, Pa: Lippincott Williams \& Wilkins.

3. Ngeow WC, Chai W. The clinical anatomy of accessory mandibular canal in dentistry. 2020;(October 2018):1-14.

4. Lory JM, Pompa JA, Kjer I. The Human Mandibular Canal Arises from Three Separate Canals Innervating Different Tooth Groups. 1996;

5. Wolf KT, Brokaw EJ, Bell A, Joy A. Variant Inferior Alveolar Nerves and Implications for Local Anesthesia. 3006(16):84-90.

6. Sarkar S, Mondal S. Bi fi d Mandibular Canals: A case report and mini review. 2020;10-2.

7. Bifid mandibular canals in panoramic radiographs. 1985;110(June):923-6.
8. Freitas GB De, Freitas A De, Morais LA, Bortolotto M, Silva F, Coelho T, et al. Incidence and classification of bifid mandibular canals using cone beam computed tomography. 2015;14(4).

9. Claeys V, Wackens G. Bifid mandibular canal: literature review and case report. 2005;55-8.

10. Kuribayashi A, Watanabe H, Imaizumi A, Tantanapornkul W, Katakami K, Kurabayashi T. Bifid mandibular canals: cone beam computed tomography evaluation. 2010;235-9.

11. Pataky L, Ne Z. Clinical Studies Atypical Courses of the Mandibular Canal: Comparative Examination of Dry Mandibles and X-Rays. 2006;2:487-91.

12. Nasseh I, Aoun G. Bifid mandibular canal: a rare or underestimated entity? 2016;6:735.

13. Clinical N. Bifid canals: identification of three clinical cases using cone-beam computed tomography images. 2018;66(3):263-6.

14. Monson LA. Bilateral Sagittal Split Osteotomy. 2013;1-4.

15. Report C. Bifid mandibular canal: An unusual presentation. 2015;453-6. 